\section{CPD FOR DENTAL HYGIENISTS AND DENTAL THERAPISTS}

Finding CPD that has been created especially for dental hygienists and dental therapists is no easy feat, especially if you earn your CPD by attending events aimed at the whole dental team.

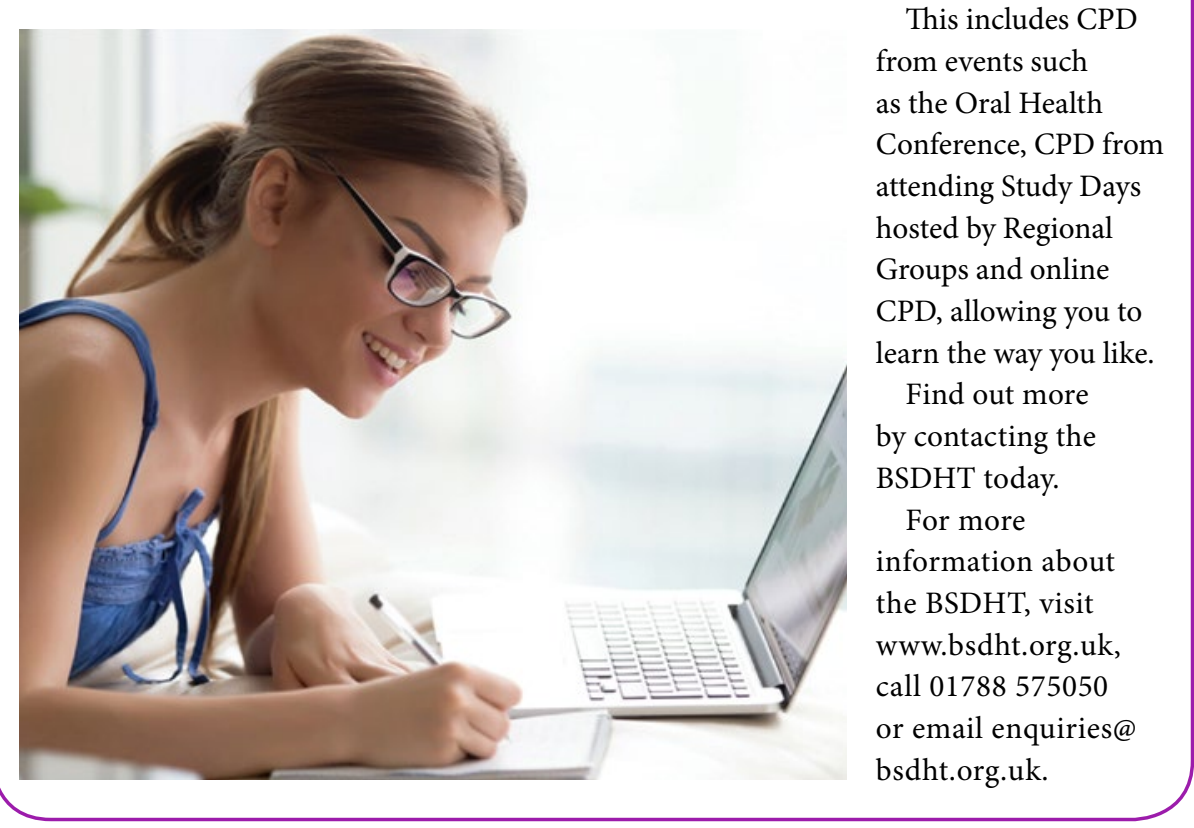

\section{ENGAGING WITH PATIENTS}

Dental hygienist Faye Donald will present in the Hygienist \& Therapist Symposium at the British Dental Conference and Dentistry Show 2020.

Faye said: 'I will be looking at the role of good, daily, self-performed oral hygiene regimes in managing oral health. I will explore the possible hurdles and road blocks we might face with regards to engaging patients in oral hygiene education. I will also demonstrate how we can use everyday resources to adopt an effective biofilm management approach and look at language the whole team can use to help shift the focus from scale and polish procedures to prevention.

'The British Dental Conference and Dentistry Show is a fabulous event. Relevant topics are delivered by clinicians facing the same day-to-day challenges as delegates, which makes them truly relatable.'
By joining the British Society of Dental access to tailored CPD that has been specifically designed to appeal to dental hygienists and dental therapists.

This includes CPD from events such Conference, CPD from Days sted by Regional Find out more by contacting the BSDHT today.

For more information about the BSDHT, visit call 01788575050 bsdht.org.uk.

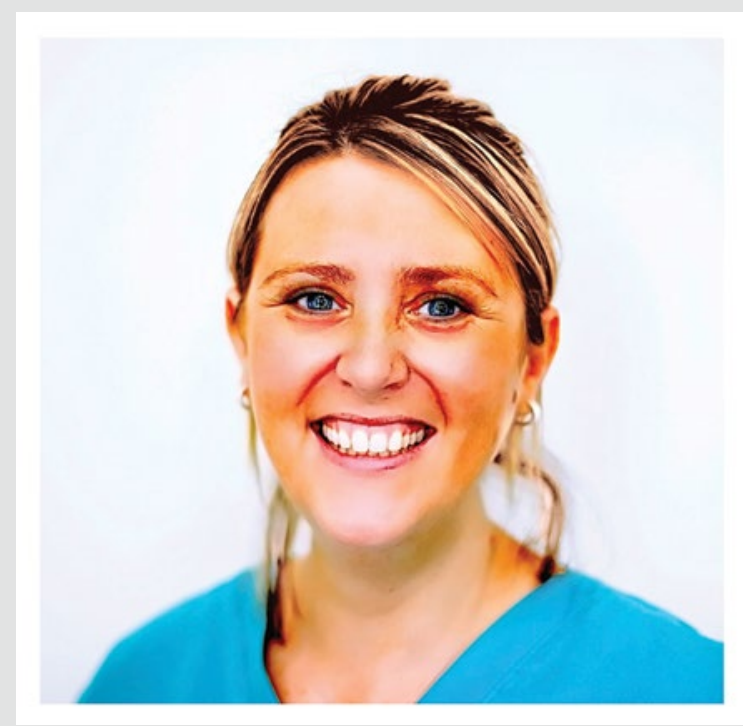

Register online for free today.

The British Dental Conference and

Dentistry Show 2020 - 11 and 12 September

- Hall 5, Birmingham NEC, co-located with DTS.

For all the latest information or to register for free, visit www.thedentistryshow.co.uk, call 02073485270 or email dentistry@ closerstillmedia.com. Hygiene and Therapy (BSDHT) you gain as the Oral Health
CHOOSE THE RIGHT ORAL HEALTH PRODUCT

In a crowded market, choosing the right oral health products can be confusing - for patients and practitioners supporting them.

TANDEX is adding international standard ISO and PHD (passage hole diameter) numbers to the packaging of its FLEXI interdental brushes. This makes it easier to understand which brush is suitable for each user.

The ISO defines what PHD interval the brush can be squeezed into without deformation. PHD is based on the number of filaments per $\mathrm{cm}$, nylon thickness per $\mathrm{mm}$ and how hard the brush is twined.

It's a simple system and new for 2020 .

For more information on Tandex's range of products, visit www.tandex.dk.
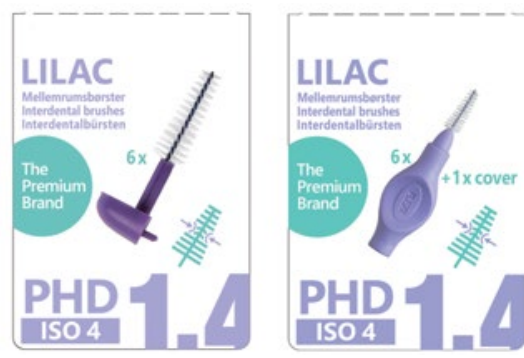

\section{WATERFLOSSING IS A WINNER}

The Waterpik Water Flosser is safe and effective for almost all patients. It is clinically proven to be up to $50 \%$ more effective at reducing gingivitis, up to $93 \%$ more effective for reducing bleeding and can remove up to $29 \%$ more plaque than string floss.

Also, the Waterpik Water Flosser delivers better results than string floss for patients with orthodontic appliances and dental implants. Plus, there is a model to suit everyone too - take a closer look at the extensive Waterpik product range now.

For more information on Waterpik products visit www.waterpik.co.uk.

Waterpik products are available from Amazon and online at Asda, Boots and Superdrug. 